\title{
An Up-to-date Survey in Barriers to Open Innovation
}

\author{
Rachid Oumlil ${ }^{*}$, Carlos Juiz ${ }^{2}$
}

\begin{abstract}
Open Innovation (OI) is recently recognized as a key factor in the competitiveness of companies. Firms that are not engaged in OI practice risk of becoming uncompetitive. However, innovating firms are likely to face several challenges often illustrated by barriers. Many researchers studied OI barriers without giving importance to their category. The main objective of this survey is to identify and categorize some barriers to OI practice by analysing how the literature on this topic has evolved for the last seven years (2009-2015). Our understanding of OI barriers can be insightful for future research on OI and it can assist managers, in fostering an innovative culture by supporting new ideas and avoiding an attitude that creates resistance towards these ideas.
\end{abstract}

Keywords: Innovation; open innovation; barriers; categorization.

Submitted: April 27th 2016 / Approved: September 12th 2016

\section{Introduction}

In the past century innovation was increasingly seen as the most important success factor of the companies' organizational performance, regardless their size and the industry they belongs to (Bigliardi et al. 2013). Many companies have been able to reinvent themselves with successful innovation projects (Pontiskoski and Asakawa, 2009). Results of the American Management Association Survey revealed the main importance of the innovation in the success of businesses (Jamrog, 2006). Innovation is considered extremely important for the company's long-term survival.

However, innovation has been defined in different ways. Booz, Allen and Hamilton (1983) considered innovation as a linear process of sequential events from research and idea generation to commercialization. Otherwise, it is as a process through which ideas are transformed into new products, services or processes (Baregheh et al., 2009). Besides, Damanpour (1991) defined innovation as "an idea or behaviour, whether a system, policy, program, device, process, product or service, that is new to the adopting organization". For Weerawardena (2003), innovation is the capacity of a firm to perform a range of coordination actions in order to deliver new products and new services to the market, in a way that surpasses competitors. Innovation is defined as a process through which ideas are transformed into new products, services or processes (Baregheh et al., 2009).

Indeed, innovation is performed on the basis of the knowledge of the people involved in its process. However, many authors stated that innovation is often driven from the contingency p eculiarities particularly related to firms' competition, deregulation, scarcity of resources, and customer demand (Damanpour and Schneider, 2009). In this sense, Rothwell (1992) includes internal interaction between departments and external interaction between the firm and its customers, partners, and suppliers. This is due to the hype of the knowledge society where information and knowledge are accessible and being a part of the competitiveness of organizations and also individuals (Coras and Tanatau, 2012). Moreover, companies cannot avoid the impact of the current environment variations such as: intensified competition, broad and fast knowledge diffusion, and rapid growth of R\&D investments, amounts and shortness of the product and technologies life-cycles. Hence, companies should rethink about how to innovate their business and their processes.

Today companies are conscious of the constant flow of novel ideas for their innovation process. They continually pay close attention to users, as a source of valuable feedback and relevant use case experiences. They integrate outside knowledge and ideas, research projects, and concepts into their own offering. Furthermore, the ubiquitous of Information Technology advances has rendered organizational boundaries very porous; by the way they allow the facilitating knowledge transfers inward and outward (Whelan et al., 2010). Moreover, the traditional resource-based view into a firm would harm and hinder today's innovation practice. Accordingly, companies should find new ways to do things. Interestingly they could focus only on what they are good at and outsource what they cannot do themselves. They could also integrate outsides ideas, new knowledge into their own offering, and then migrate from the traditional to a modern practice of innovation called open innovation.

Open Innovation (OI) is considered as a new paradigm of innovation, where organizations innovate with partners to share risks and rewards. It is popularised by its initiator Chesbrough (2003), as an opposite to the traditional paradigm of innovation: 'closed innovation'. Unlike this later, where companies innovate relying on internal resources only, in OI, company boundaries become porous and allow resources integration between the company and external collaborators (Chesbrough, 2003). OI is a new practice regarding the manner in which firms conduct and commercialize innovation outputs (Liaocet al., 2014). It is defined as 'the use of purposive inflows and outflows of knowledge to accelerate internal innovation, and to expand the

(1) LaRGe,ENCG-Agadir, University Ibn Zohr, Morocco

(2) Computer Science, University of the Balearic Islands, Palma de Mallorca, Spain

*Corresponding author : r.oumlil@uiz.ac.ma 
markets for external use of innovation, respectively', (Chesbrough et al., 2006). Hence, OI invites actors outside the organization to pursue innovation driven either by non-profit (Kuk and Davies, 2011) or profit (Ceccagnoli et al., 2011) motivations. Rice et al. (2012) noted that OI acts as an innovation catalyser and will never overcome fundamental deficiencies or ineffective systems and capability configurations elsewhere in the company.

Moreover, OI has been catalysed through the ubiquitous of Information technology. This later allows access to a bulk quantity of data in a more open fashion, throughout the outside innovators (Boudreau and Lakhani, 2009). Moreover, regarding Chesbrough (2003) three main factors are behind the migration towards this practice: (1) the increasing availability and mobility of knowledge workers (2) the flourishing of the Internet and venture capital markets, and (3) the broadening scope of possible external suppliers. Mortara et al. (2008) added four other reasons behind this migration: (1) Reducing time to market for products (2) Availability of new technologies (3) Access to competencies (4) Exploitation of internally developed technologies.

Today, OI practice is perceived by companies as means to improve their innovation performance (Huang et al., 2015) and accelerate its rate (Lam et al., 2013). Indeed, it has been adopted first in the high-tech sectors (Chesbrough, 2003; Kirschbaum, 2005), and then emerged within low-tech sectors, such as the industry (Holmström and Westergren, 2012), small and medium-sized enterprises (SMEs) (Gassmann et al., 2010; Henkel, 2006; Lee et al., 2010; Parida et al., 2012; Rahman and Ramos, 2013), food industry (Fortuin et al,. 2009), etc. The majority of extant research on OI is drawn from firms operating in North America and Europe (Chaston and Scott, 2012). Subsequently, OI practice is still limited and requires more application. For this issue, we research about OI barriers as drawbacks to foster its application.

The extensive literature written on open innovation subjects highlights the motivations and the benefits of the OI. Nevertheless, studies about OI barriers are still limited and none of these researches has gone over the classification of OI barriers. Given these limitations, we consider of high weight the need to stress on these barriers. Hence the aim of this survey is to fill this gap by reviewing and classifying by categories the main current barriers toward innovation practice. We referred to key concepts related to barriers or obstacles of OI cited in researches published since 2009. Moreover, by undertaking this paper, we purpose two main objectives: (1) to beef up the scarce literature on open innovation barriers by providing a basis on OI barriers, (2) to shed light on the factors that a firm needs to approach in order to foster a culture for open innovation.

We have structured this paper as follows. Section 2 provides the theoretical basis for OI paradigm. Section 3 reviewed recent researches related to OI barriers and present a meta-analysis of the OI barriers. In section 4 we conclude and highlights some managerial implications and paths for furthers researches.

\section{Open Innovation Paradigm}

Indicate Nowadays, organizations are faced to many challenges, varying from complex tasks to creation of the competitive advantage and surviving in the dynamic environment (Dess and Picken, 2001). Innovation is considered the main key to overcome these challenges. It is seen as the bloodline of any organisation aiming to succeed in such environment (Schulze et al., 2012). Lichtenthaler and Lichtenthaler (2010) stated that traditionally, innovation was sticked to Research \& Development (R\&D) departments, where importance was devoted to the internal knowledge only, so that off-the-wall ideas were less interesting. Afterwards, the abundant knowledge due to the massive usage of IT obliged companies to not entirely rely on their own ideas to innovate. Subsequently the emergence of a new paradigm called: Open Innovation (OI).

In 2003, Henry Chesbrough introduced the concept of OI. His research works at Xerox PARC (Chesbrough \& Rosenbloom, 2002), IBM, Intel and Proctor \& Gamble, revealed the firm necessity to innovation strategies allowing innovation flows across firm boundaries and outlined the role of company-to-company partnerships. Furthermore, OI has become one of the critical topics in innovation management literature (Chesbrough, 2003; Christensen et al., 2005; Gassmann, 2006;Westergren and Holmström, 2012). It has quickly gained the interest of practitioners and researches from a wide range disciplines, including economics, psychology, sociology, and even cultural anthropology (Von Krogh and Spaeth, 2007).

Chesbrough (2006) defined OI as "The use of purposive inflows and outflows of knowledge to accelerate internal innovation, and expand the markets for external use of innovation, respectively. [This paradigm] assumes that firms can and should use external ideas as well as internal ideas, and internal and external paths to market, as they look to advance their technology" (Chesbrough et al, 2006, p.1). Otherwise, it explains the way of innovation when a company provides internally generated knowledge for the market and external knowledge flows in. For West et al. (2006, p.286), OI is described as "both a set of practices for profiting from innovation and a cognitive model for creating, interpreting and researching those practices". West and Gallagher (2006) added that OI is a wide range of internal and external sources for innovation opportunities consciously integrated with firm capabilities and resources, and broadly exploiting those opportunities through multiple channels.

OI explains how firms would enhance their innovative performance by exploitation external knowledge, as well as how they would benefit financially by using external paths to market (Chesbrough, 2003; Gassmann and Enkel, 2004). It aims to accelerate internal innovation, and to expand the markets for external use of innovation respectively (Chesbrough et al., 2006). It incorporates accumulation of ideas, knowledge, licenses, intellectual properties, patents, and inventions (through licensing, joint ventures, spin-offs). In addition, internal inventions that are not being used in a company's business process 
should be taken outside the company (through licensing, joint ventures, spin-offs) (Chesbrough and Crowther, 2006). Hence, OI could be seen as a combination of two differently directed processes: inbound and outbound. From other side, Enkel et al. (2009) proposed to combine the inbound activities with outbound activities in order to co-develop, commercialise and co-capitalise on innovation. In the "open" innovation model, companies make use of external ideas and competence, to strengthen its own innovation capabilities (Chesbrough 2003; Gassman 2006; Mortara et al., 2009). Thus, open innovation is paradigm assuming that firms can and should use internal and external ideas, and internal and external paths to market, as the firms look to advance their technology (Chesbrough, 2003)

West and Gallagher (2006) identified three main inherent management challenges related to: (1) maximization that include outbound IP licensing and patent pooling (2) incorporation where firms should identify relevant knowledge through scanning, recognitions, absorption and political willingness to integrate external innovation and (3) motivation in witch firms have to assure continued supply of relevant external technologies and IP. Instead of relying on its own R\&D department to enhance the company innovation abilities, the open innovation model mobilises the key organisational networks and players (suppliers, customers, public and private research centres, institutions, universities and even competitors) (Clausen and Pohjola, 2009; Piperopoulos, 2012)

Despite of being widely researched, there is no clear consensus upon what constitutes open innovation practices, however, it has been defined as an antithesis of its predecessor, "closed" innovation, (Bullinger et al 2012), where companies relied on internal channels for research, development and commercialization of their inventions (Chesbrough 2003; Gassman and Enkel, 2004). It figures out that firms should use external ideas and internal and external paths to market, as the firms look to advance their technology (Chesbrough, 2003).

Traditionally innovation takes an importance place within companies and has been the way several industries operated. It started closed where firms look beyond their internal environment and limited resources for knowledge, ideas, opportunities and partners, (Chesbrough, 2003; Spithoven et al., 2012). This way is called the vertical integration model or the closed innovation paradigm. This paradigm refers to an understanding that successful innovation requires also control processes (Pontiskoski and Asakawa, 2009). Moreover, research and development activities within organizations are considered strictly internal processes and should be guarded from external influences (Westergren and Holmström, 2012). In the sense of Chesbrough (2003), companies have to bring out their ideas and then to develop them, build them, market them, distribute them, service them, finance them and support them on their own in the closed paradigm. Otherwise, ideas should be generated in-house and the only way to market them is through the originating firm (Chesbrough, 2006 b). Besides, companies should be strongly self-reliant, because one cannot be sure of the quality, availability, and capability of others' ideas (Chesbrough, 2003). Also, the closed paradigm supposes that innovation must be kept in-house and the intellectual property generated through $\mathrm{R} \& \mathrm{D}$ department is a trade secret.

Although the closed innovation paradigm worked well for quite some time and many, the current innovation landscape has changed (Vrande et al., 2009). Hence a many developments within and outside the innovation arena revealed the ineffectiveness of the traditional innovation system and engender the necessity to change the innovation process and migrate to the open one. These developments consist of knowledge workers and information technology breakthroughs, the increased mobility of workers, the growing presence of venture capital, the increasingly shortened product life cycles, the growing competition, the globalization of economy, the improved use of information technology, and the wide availability of knowledge from multiple sources engendered the outdate of the closed innovation and the migration the OI paradigm (Rahman and Ramos, 2010). Based on Chesbrough (2003) assumptions, the open paradigm is driven by four main factors: (1) The increased availability and mobility of skilled "knowledge-workers", (2) the new external options available for unused ideas, (3) the external suppliers increasing capability and finally, (4) the emerging venture capital markets that created new strategic opportunities for companies.

The OI paradigm assumes that firms should use external ideas as well as internal ones, internal and external paths to market, as the firms look to advance their technology (Chesbrough, 2006). Otherwise, it refers to a strategy and business philosophy where companies actively look for both internal and external ideas' sources to accelerate their innovation process. It is an emerging paradigm that is based on the fact that external ideas and internal paths are placed at the same level of importance. Referring to Chesbrough et al. (2006), OI paradigm can be understood as the antithesis of the traditional paradigm. It is seen as the use of purposive inflows and outflows of knowledge and ideas for both accelerating internal innovation and expanding the markets for external use of innovation.

The open innovation paradigm provides a new perspective towards external collaboration. It acknowledges that companies have a strong interest to partner and to integrate external sources of knowledge. Innovation becomes, then, a collective activity integrating a great number of stakeholders for production and R\&D. in the same sense, Lichtenthaler (2011) suggested two main OI characteristics distinguish from the innovation collaborative approaches: (1) the integration of inward and outward knowledge transfer, and (2) the complementary character of internal and external innovation. By adopting an OI paradigm, firms can pursue it in three different ways: (1) engagement in enriching their own skills and knowledge through the integration of stakeholders (suppliers, customers,...) into the internal innovation process (Enkel et al. 2009), (2) carry out outbound OI activities by bringing ideas, patents, and any intellectual property rights form to the market (Lichtenthaler, 2008) and (3) co-creation with complementary partners (Enkel et al., 2009) that combine the outbound and inbound OI activities. Table 1 summarize peculiarities of open and closed innovation paradigms. 
Table 1. Inspired from Closed Innovation Vs Open Innovation Chesbrough, H. W. (2003 b)

\begin{tabular}{|c|c|}
\hline Open Innovation & Closed Innovation \\
\hline $\begin{array}{l}\text { Not all of the smart people work for us" so we must find and tap into the } \\
\text { knowledge and expertise of bright individuals outside our company }\end{array}$ & The smart people in our field, work for us \\
\hline $\begin{array}{l}\text { External } R \& D \text { can create significant value; internal } R \& D \text { is needed to claim } \\
\text { some portion of that value }\end{array}$ & To profit from R\&D, we must discover, develop and ship it ourselves \\
\hline We don't have to originate the research in order to profit from it & If we discover it ourselves, we will get it to market first \\
\hline Building a better business model is better than getting to market first & If we are the first to commercialize an innovation, we will win \\
\hline If we make the best use of internal and external ideas, we will win & If we create the most and best ideas in the Industry, we will win \\
\hline $\begin{array}{l}\text { We should profit from others' use of our IP, and we should buy others' IP } \\
\text { whenever it advances our own business model }\end{array}$ & $\begin{array}{l}\text { We should control our intellectual property (IP) so that our competitors don't } \\
\text { profit from our ideas. }\end{array}$ \\
\hline
\end{tabular}

\section{Barriers to Open Innovation (OI)}

In 2009, Pontiskoski and Asakawa, described in a conceptual paper, how companies overcame barriers to use open innovation strategy in $\mathrm{R} \& \mathrm{D}$ and commercialization projects. The two authors studied three companies able to reinvent themselves and their business: Nokia nseries, Nintendo Wii, and Apple iPod. They compared three of their product development and commercialization projects. Their objective was about comparing and contrasting open innovation success factors and pitfalls from the three companies. To do this, they exploited secondary data related to the cited companies, and then they identified three levels of open innovation barriers: cognitive, behavioural, and institutional.

Mortara et al. (2009) tried to identify barriers and challenges related to implementation of OI in companies belonging to divers sectors (Fast moving consumer goods, Energy and oil, Aerospace and defence, Software and media, Electronics and telecommunication, Intermediaries such as knowledge and service brokers). Methodologically, they interviewed 26 managers of these companies and underlined the influence of several barriers ranging from internal cultural issues, lack of appropriate skills, lack of resources and appropriate structural change.

In the same intent, Fortuin and Omta (2009) attended to find out the main drivers and barriers to open innovation in the food processing industry in Netherlands. Also, they explored how far this industry can rely on the principles of innovation management developed in high-tech industries to improve its innovation performance. The two authors referred to the theoretical insights derived from the industrial organization theory and the resource-based view to develop their questionnaire. Results of the data collected from research director, CTO, or CEO of the nine companies participating in the study, light out the importance of the barriers related to the underutilization of open innovation in the food industry.

Vrande et al. (2009) explored barriers for open innovation in SMEs, acting in manufacturing and service industries. They used a survey database collected by EIM, a Dutch institute for business and policy research, in December 2005. The authors suggested many OI innovation barriers ranging from, administration, finance, knowledge, marketing, organizational culture...

In 2010, Hernandez-Mogollón et al. studied the role of cultural barriers in the relationship between open-mindedness (OM) and organizational innovation towards SMEs. The study was conducted in a population of 57.000 firms of the Extremadura region, Spain. Authors adopted a simple aleatory sampling and mailed their questionnaire to the selected SMEs. Their finding exposed the impact of the cultural barriers on the relationship between OM and organizational innovation in these enterprises. In the same context of SMEs, Rahman and Ramos (2010) emphasized various open innovation strategies by focusing transformation of innovation process from closed boundary to networked paradigm. They tried to provide an overview on innovation strategies and to discuss about some challenges and barriers that SMEs are facing in implementing OI strategies. To identify these barriers, the two authors referred to the contributions of Hadjimanolis (1999) and Rush and Bessant (1992).

As for Savitskaya et al. (2010), they proposed to analyse the barriers to open innovation from three different aspects: (1) internal firms' environment, (2) institutional factors or innovation system and (3) cultural background. They targeted around 800 companies in the Yunnan province (China) and collected their data through email and a paper survey, and also by phone, in a few cases. The authors were limited on the following factors considered as the main barriers to manufacturing and service sectors OI companies: Not-invented here syndrome, no adequate technologies on offer, fear of losing own innovation ability, lack of marketplaces for technologies and not-sold here complexity of IP rigths and fear of infringements.

Lee et al. (2010) investigated three main problems: (1) to place the concept of open innovation in the context of SMEs (2) to suggest the input of an intermediary in facilitating innovation and (3) to report 
accounts of Korean SMEs' success in working with an intermediary. They pointed up many barriers to OI in the SMEs Korean context: Difficulties in finding suitable manpower in a labour market, market uncertainty in innovative products, imitation possibilities of technology innovation, short of ability in R\&D planning and management, lack of market information, frequent turnover human resources (usually for R\&D),...

Holmström \& Westergren (2012) studied indirectly barriers to OI by exploring its preconditions in iron ore mining sector and highlighted the critical influence of trust. Besides, Lüttgens et al. (2012) attempted to identify both critical incidents that may occur during the implementation of crowdsourcing in the innovation process and also to derive suggestions for organizational interventions to overcome these barriers. To do, they based on a design science approach and a longitudinal study of six companies engaged in piloting of open innovation.

In 2013, Lam et al. purposed to understand drivers and barriers to OI type called the Industry-University Collaboration (IUC) in Hong Kong. They hypothesised that these drivers and barriers ranged from unavailability of competent external partners to provide the necessary knowledge and technologies, fear of disclosing their own intellectual property to external partners, innovation too easy to copy, or lack of demands from clients/customers for generation of knowledge and technologies, existing legislation, norms and regulations,...

In their conceptual paper, Coras and Tantau (2014) stressed on the benefits, the barriers and the drawbacks entailed by open innovation projects. They explored the incentives of firms embarking in collaborative relationships, and the diversity of risks entailed. They revealed many barriers related to: Workforce, knowledge sharing, collaboration, market, clients finance technology and intellectual property. Furthermore, Hjalmarsson et al. (2014) proposed a framework of OI barriers to of digital services. This framework has been designed using a systematic research approach including a literature review of existing barriers related to cost, finance, innovation, knowledge, market, organization, strategy, regulation, society and technology.

Recently, McCormack et al. (2015) conducted a research to identify drivers and barriers to adopt OI in Galway MedTech cluster in Ireland. They firstly classified these barriers into many categories: Knowledge, marketing, organisation culture, property rights, quality of partners, competence of employees, commitment and idea Management, and secondly they administrated an online survey to a population of 43 companies. Moreover, Janevski et al. (2015) focussed on SMEs and studied level of awareness and constraints for adoption of open innovation strategies in the Republic of Macedonia. Authors conducted a survey among 63 firms and investigated barriers related to many category constraints of the Macedonian context: Recruiting constraints, general constraints, competition constraints, and policy constraints. With the similarly research subject, Nafi et al. (2015) examined the issues and challenges facing the implementation of OI among the SMEs in Malaysia. They inspected the issue of trust and its relation to the study of open innovation and collaborative networks.

\section{Categorizing the Open Innovation Barriers}

barriers. Selection was based on the following criteria. We primary conducted computerized keyword searches related to Barriers to OI, lacks of OI, and obstacles of OI. We limited the selection to articles that were related to the subject areas 'Management' or 'Business', 'Information Technology' and that were published in the following scientific databases: Ebscohost, Scopus, ISI Web of Knowledge, ABI Inform and Google scholar. Second, we manually searched abstracts from these databases. Then we examined the references from the articles identified in these previous steps to locate additional studies that the other searches were unable to capture. Third, we removed duplicates and articles that were deemed not applicable by the authors.

The final sample consisted of 19 articles published within the last seven years (2009-2015) that handled research questions related to OI barriers. Of these 19 articles, four were published respectively in 2009 and 2010, two in 2012, two in 2013, three in 2014 and four in 2015. Furthermore, we selected barriers used within these 19 articles and we conducted a lexical analysis in order to classify them by category. For this issue, we used two Project R software (R Core Team, 2014):

a. Rstudio software for a lexical analysis order to identify the common themes between these barriers and the statistical analysis.

b. RQDA software to classify the barriers by category

Choice of the Project R software is due to the fact that this environment provides a powerful and flexible system for statistical computations. It is considered powerful enough for performing analyses, comparable to other software, e.g. Nvivo, SAS, SPSS (Mangiafico, 2013). Wordcloud package is used to visualise the dominant words within the barriers sentences. Results revealed the dominance of the following words: Management, Market, Knowledge, partners, technology, trust, and extern, etc. are shown in Figure 1. From these words, we generated six general themes related theses dominant words:

- Environmental (Env)

- $\quad$ Managerial and Organizational (Mgm \& Org)

- $\quad$ Individual (Ind)

- $\quad$ Cultural (Cult)

- Innovative (Inn)

- $\quad$ Processual (Pro) 
Figure 1. Wordcloud of the dominant words within the barriers sentences

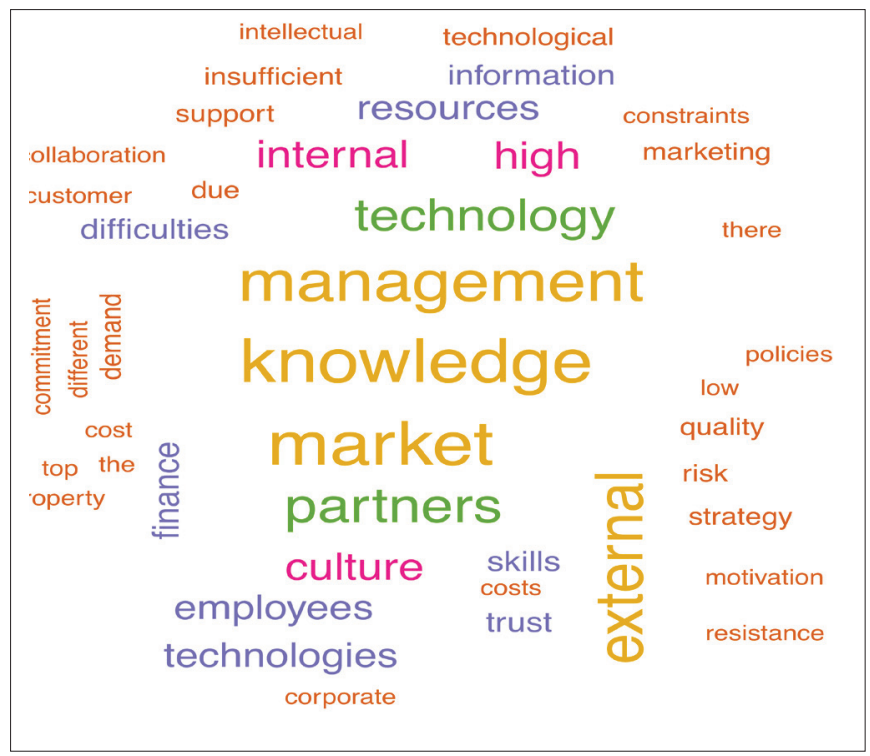

After fixing up the general themes related to the dominant words, we performed a classification of the identified barriers. Table 1 (index) gathers all the barriers used within the 19 articles arranged by theme, by country and by sector. For example, Lüttgens et al. (2012) cited 13 barriers: (1) Negative Attitude, (2) Intellectual property management, (3) Workflow rigidity, (4) NIH (not-invented-here) syndrome, (5) Lack of internal commitment, (6) Bottom-up management, (7) Insufficient resources, (8) Allocating wrong task to pilot, (9) Insufficient top management support, (10) Unrealistic expectation, (11) Legal barriers, (12) Organizational / Administrative barriers and (13) Communication barriers. However, a direct exploitation of these barriers risks to be reductive, whence the reason behind the necessity to classify them. By the way, it becomes easy for managers, CEO and innovators to master the general level of barriers (that could be Individual, Organizational...) instead of analysing them directly. Thereby, for Lüttgens et al. (2012), we identified four main categories of barriers allocated as follow:

- Environmental Barriers: Legal barriers;

- Managerial and organizational Barriers: Intellectual property management, Bottom-up management, Insufficient resources, Allocating wrong task to pilot, Insufficient top management support, Unrealistic expectation, Organizational/ Administrative barriers, and Communication barriers;

- Individual Barriers: Negative Attitude, Workflow rigidity, Lack of internal commitment, and Insufficient top management support

- Cultural Barriers: NIH (Not-Invented-Here) syndrome
Classification in Figure 2 allows the comparison between categories of barriers. The managerial and organizational barriers (38.4\%) are the most cited and exploited barriers, followed by the environmental $(27.9 \%$, then the individual (16.7\%) and the cultural (10.9\%). The last places are respectively occupied by the Innovative (5.4\%) and the processual $(0.8 \%)$ ones.

Figure 2. Repartition of barriers by category

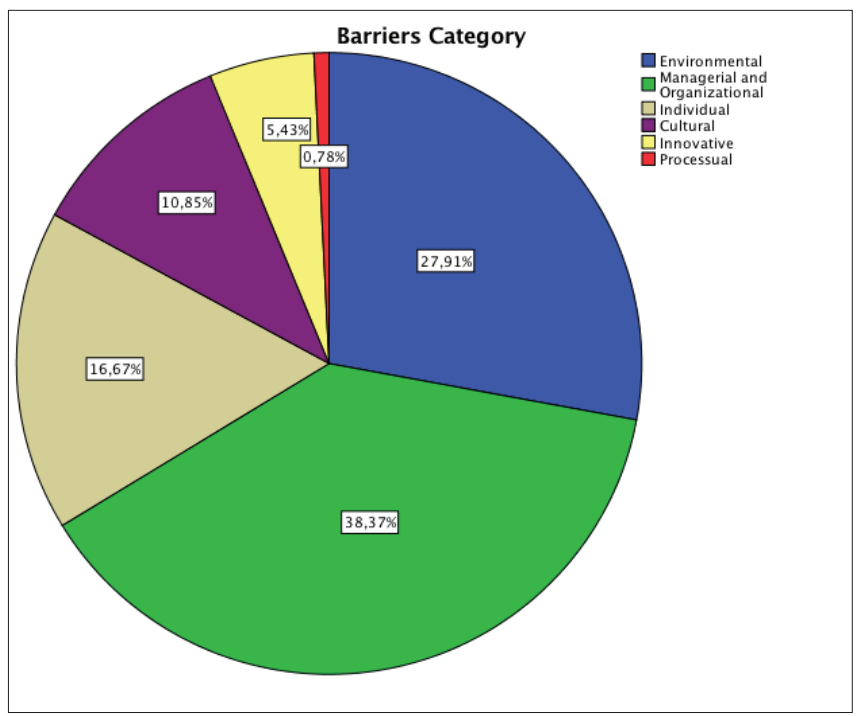

Moreover an intersection between the category of barriers and the activity sector expose the dominance of barriers tested in SMEs, followed by industry (Table 2). The digital services sector and IT came in the fourth position. This intersection proved the great intention given to open innovation and its barriers in SMEs. This is due to the fact that this category of firms could be the most concerned with the OI practice. Otherwise, the correlation test between OI barriers and sector pointed out a positive non-significant relationship between category of barriers and type of sector $(r=$ 0.269). Hence, explication of OI barriers could not be limited on the characteristics of the activity sectors only. They could be related to the country peculiarities also. 
Table 2 Cross tabulation barriers category and Sector

\begin{tabular}{|c|c|c|c|c|c|c|c|c|c|}
\hline \multicolumn{10}{|c|}{ Barriers Category ${ }^{*}$ Sector Cross tabulation } \\
\hline & & \multicolumn{7}{|l|}{ Sector } & Total \\
\hline \multirow{4}{*}{$\begin{array}{l}\text { Barriers } \\
\text { Category }\end{array}$} & Environmental & 23 & 1 & 0 & 14 & 5 & 17 & 12 & 72 \\
\hline & $\begin{array}{l}\text { Managerial and } \\
\text { Organizational }\end{array}$ & 33 & 8 & 0 & 10 & 6 & 17 & 25 & 99 \\
\hline & Individual & 13 & 4 & 0 & 5 & 4 & 10 & 7 & 43 \\
\hline & Processual & 0 & 0 & 0 & 0 & 0 & 1 & 1 & 2 \\
\hline \multicolumn{2}{|l|}{ Total } & 78 & 14 & 1 & 40 & 16 & 51 & 58 & 258 \\
\hline
\end{tabular}

Table 3 disclose the relationship between OI barriers and countries. Results revealed the dominance of Sweden followed by Germany in investigating the OI barriers. These results allowed concluding the attention given by these two countries to the OI practice and the desire of its dissemination. Moreover, managerial and organizational barriers marked high score for both of Sweden (27) and Germany (24). This explains the attentiveness that firms should devote to managerial and organizational barriers whenever they wish adopt an OI practice.
Furthermore, a correlation test was performed to study the relationship between category of barriers and countries. Results indicated a very week correlation between the two variables $(r=0.015)$. Otherwise, dominance of OI barriers does not necessary implies the country commitment in OI practice.

Table 3. Cross tabulation barriers category and countries

\begin{tabular}{|c|c|c|c|c|c|c|c|c|}
\hline \multicolumn{9}{|c|}{ Country ${ }^{\star}$ Barrier Category Cross tabulation } \\
\hline & & \multicolumn{6}{|c|}{ Barrier_Category } & \multirow[b]{2}{*}{ Total } \\
\hline & & Environmental & $\begin{array}{l}\text { Managerial } \\
\text { Organizational }\end{array}$ & and ${ }_{\text {Individual }}$ & Cultural & Innovative & Processual & \\
\hline \multirow{11}{*}{ Country } & Germany & 8 & 24 & 10 & 4 & 1 & 0 & 47 \\
\hline & Italy & 1 & 3 & 1 & 0 & 0 & 0 & 5 \\
\hline & Netherlands & 0 & 0 & 0 & 1 & 0 & 0 & 1 \\
\hline & China & 1 & 1 & 0 & 1 & 1 & 0 & 4 \\
\hline & Norway & 0 & 0 & 1 & 0 & 0 & 0 & 1 \\
\hline & UK & 0 & 4 & 4 & 4 & 0 & 1 & 13 \\
\hline & Malaysia & 0 & 0 & 1 & 0 & 0 & 0 & 1 \\
\hline & Hong Kong & 7 & 4 & 1 & 1 & 1 & 0 & 14 \\
\hline & Finland & 2 & 1 & 2 & 2 & 1 & 0 & 8 \\
\hline & Korea & 5 & 7 & 1 & 0 & 2 & 0 & 15 \\
\hline & Macedonia & 3 & 3 & 3 & 0 & 0 & 0 & 9 \\
\hline
\end{tabular}

\section{Conclusions and further research}

The objective of this paper is to broaden the scope of research about Open Innovation (OI) throughout a categorization of its barriers. It presents practically the barriers' approach toward OI practice. This approach could be seen as a powerful mean to better explain individual and organizational behaviours. It could help to foster OI adoption and even solve problems related to its applicability. Indeed, the barriers approach to OI could be considered a meaningful approach in explaining success factors of OI practice. Our work is an innovative in identifying obstacles and problems that organizations and managers have to advance innovative activities. However, further research is needed in finding efficient tool measurements for OI barriers and drawing effective and practical conclusions.
We chose a sample descriptive meta-analysis to account for the limitation of researches studding barriers to OI. We aim for categorizing these barriers and subsequently building a standardized measurement tool for OI barriers. Further researches are probably required to explore and examine barriers by categories and in more detail. They could exploit results of this conceptual paper, especially barriers categorization, to build new constructs explaining OI innovation practice from one or both of the following approaches: organizational, individual, environmental, cultural, innovative or processual. This categorization enables to enrich the findings on barriers to OI and could provide answers to questions of strength and importance of these barriers quantitatively. Moreover, the present study revealed that the barriers to OI are not equal in sectors and even in countries, it could be necessary to develop specific barriers' tool that takes into consideration the differences between organization, activities and countries. 
Indeed, OI affects companies' capacity to compete successfully in an increasingly global market. Hence, understanding its barriers can help in the company strategies and policies government development that contribute to economic growth and increased wealth. This paper shows the importance of understanding categories of OI barriers, especially when expressing innovation intention. More attention on OI barriers category can lead to an effective joint action for open innovation promotion. This approach is important especially when the firm is not highly innovative. Barriers assessment becomes a crucial step to its engagement in open innovation practice. Besides, understanding OI barriers can afford to managers tools to foster an open innovative culture within their firms by avoiding negative attitude. An alignment between OI culture and the firm's business strategies can engender great efficiency and efficiency and organizational success.

The insufficient number of researches studding OI innovation barriers (19 articles only) has been the major drawback performing our work. We are aware of the fact that this meta-analysis is a minor step on the road to gaining a better understanding of the open innovation barriers. Of course, there are still many uncharted categories. We hence, enumerate a number of them without having the ambition to be more exhaustive. The number of researches used in the meta-analysis is low. It could diminish the results power even when they are representative studies in the literature. We only considered six categories of barriers (environmental, managerial and organizational, individual, cultural, innovative and processual) but other typologies exist. But our effort may open a window for a future research to investigate deeply on OI barriers and generate new categories. Findings of this paper can be used in the development of companies' strategy or public policy that support and encourage open innovation practice.

\section{References}

Baregheh, A., Rowley, J., \& Sambrook, S. (2009). Towards a multidisciplinary definition of innovation. Management decision, 47(8), 1323-1339.

Bigliardi, B., \& Galati, F. (2013). Innovation trends in the food industry: the case of functional foods. Trends in Food Science \& Technology, 31(2), 118-129.

Bigliardi, B., \& Galati, F. (2013). Models of adoption of open innovation within the food industry. Trends in Food Science \& Technology, 30(1), 16-26.

Booz, A. and Hamilton. (1982). New products management for the 1980s. Booz, Allen and Hamilton Inc.

Boudreau, K., \& Lakhani, K. (2009). How to manage outside innovation. MIT Sloan management review, 50(4), 69.

Bullinger, A. C., Rass, M., Adamczyk, S., Moeslein, K. M., \& Sohn, S. (2012). Open innovation in health care: Analysis of an open health platform. Health policy, 105(2), 165-175.
Ceccagnoli, M., Forman, C., Huang, P., \& Wu, D. J. (2011). Co-creation of value in a platform ecosystem: The case of enterprise software. MIS Quarterly, Forthcoming.

Chaston, I., \& Scott, G. J. (2012). Entrepreneurship and open innovation in an emerging economy. Management Decision, 50(7), 1161-1177.

Chesbrough, H. (2003). The logic of open innovation: managing intellectual property. California Management Review, 45(3), 33-58.

Chesbrough, H. W. (2003 b). The Era of Open Innovation. MIT Sloan Management Review, 44(3), $35-41$

Chesbrough, H. W. (2006). Open innovation: The new imperative for creating and profiting from technology. Harvard Business Press.

Chesbrough, H., \& Crowther, A. K. (2006b). Beyond high tech: early adopters of open innovation in other industries. R\&d Management, 36(3), 229-236.

Chesbrough, H., \& Rosenbloom, R. S. (2002). The role of the business model in capturing value from innovation: evidence from Xerox Corporation's technology spin-off companies. Industrial and corporate change, 11(3), 529-555.

Chesbrough, H., Vanhaverbeke, W., \& West, J. (Eds.). (2006). Open innovation: Researching a new paradigm. OUP Oxford.

Christensen, J. F., Olesen, M. H., \& Kjær, J. S. (2005). The industrial dynamics of Open Innovation-Evidence from the transformation of consumer electronics.Research policy, 34(10), 1533-1549.

Clausen, T. H., \& Pohjola, M. (2009). International competitiveness: internal capabilities and open innovation as sources of export performance. Micro-Dyn Working Paper, 5(09).

Coras, E. L., \& Tantau, A. D. (2014). Open Innovation-The Good, The Bad, The Uncertainties. The USV Annals of Economics and Public Administration, 14(1 (19)), 38-47.

Damanpour, F. 1991. "Organizational Innovation: A Meta-analysis of Effects of Determinants and Moderators," Academy of Management Journal 34 (3), 555-590.

Damanpour, F., \& Schneider, M. (2009). Characteristics of innovation and innovation adoption in public organizations: Assessing the role of managers.Journal of public administration research and theory, 19(3), 495-522.

Dess, G. G., \& Picken, J. C. (2001). Changing roles: Leadership in the 21st century. Organizational dynamics, 28(3), 18-34.

Enkel, E., Gassmann, O., \& Chesbrough, H. (2009). Open R\&D and open innovation: exploring the phenomenon. R\&d Management, 39(4), 311-316. 
Fortuin, F. T., \& Omta, S. W. F. (2009). Innovation drivers and barriers in food processing. British Food Journal, 111(8), 839-851.

Gassmann, O. (2006). Opening up the innovation process: towards an agenda.R\&d Management, 36(3), 223-228.

Gassmann, O., \& Enkel, E. (2004). Towards a theory of open innovation: three core process archetypes. In R\&D management conference $6,(1), 1-18$.

Gassmann, O., Enkel, E., \& Chesbrough, H. (2010). The future of open innovation. R\&d Management, 40(3), 213-221.

Hadjimanolis, A. (1999). Barriers to innovation for SMEs in a small less developed country (Cyprus). Technovation, 19(9), 561-570.

Henkel, J. (2006). Selective revealing in open innovation processes: The case of embedded Linux. Research policy, 35(7), 953-969.

Hjalmarsson, A., Johannesson, P., Juell-Skielse, G., \& Rudmark, D. (2014). Beyond innovation contests: A framework of barriers to open innovation of digital services. In ECIS 14 22nd European Conference on Information Systems, Tel Aviv, 5-13 June 2014.

Huang, F., Rice, J., \& Martin, N. (2015). Does open innovation apply to China? Exploring the contingent role of external knowledge sources and internal absorptive capacity in Chinese large firms and SMEs. Journal of Management \& Organization, 21(05), 594-613.

Jamrog, J.J. (2006). The Quest for Innovation: A Global Study of Innovation Management 2005-2016, Human Resource Institute, University of Tampa, Tampa, Tampa, FL

Janevski Z., Davitkovska, E., \& Petkovski, V. Barriers if implementing open innovations in Macedonian SMEs. Economic, 17 (3), 93-106.

Kirschbaum, R. (2005). Open innovation in practice. Research-Technology Management, 48(4), 24-28.

Kuk, G., \& Davies, T. (2011). The roles of agency and artifacts in assembling open data complementarities.

Lam, J. C. K., Hills, P., \& Ng, C. K. W. (2013). Open Innovation: A Study of Industry-University Collaboration in. International Journal of Technology, Knowledge and Society, 8(6), 83-102.

Lee, S., Park, G., Yoon, B., \& Park, J. (2010). Open innovation in SMEs-An intermediated network model. Research policy, 39(2), 290-300.

Liao, T. S., Rice, J., \& Lu, J. C. (2015). The Vicissitudes of Competitive Advantage: Empirical Evidence from Australian Manufacturing SMEs. Journal of Small Business Management, 53(2), 469-481.

Lichtenthaler, U. (2008). Open innovation in practice: an analysis of strategic approaches to technology transactions. Engineering Management, IEEE Transactions , 55(1), 148-157.
Lichtenthaler, U. (2011). 'Is open innovation a field of study or a communication barrier to theory development?'A contribution to the current debate.Technovation, 31(2), 138-139.

Lichtenthaler, U., \& Lichtenthaler, E. (2010). Technology transfer across organizational boundaries: absorptive capacity and desorptive capacity.California Management Review, 53(1), 154-170.

Lüttgens, D., Antons, D., Pollok, P., \& Piller, F. T. (2012). Implementing Open Innovation Beyond the Pilot Stage: Barriers and Organizational Interventions.RWTH-TIM Working Paper, October.

Mangiafico, S. S. (2013). Using R-Project for Free Statistical Analysis in Extension Research. Journal of Extension, 51(3).

McCormick, K., \& Kiss, B. (2015). Learning through renovations for urban sustainability: The case of the Malmö Innovation Platform. Current Opinion in Environmental Sustainability, 16, 44-50.

Mortara, L., Napp, J. J., Slacik, I., \& Minshall, T. H. W. (2008). How to implement open innovation: Lessons from studying large multinational companies.

Nafi, S. N. M., Yusoff, R. Z., Sam, T. L., \& Saad, R. Open Innovation Among SMEs in Malaysia: The Issue of Trust. International Academic ResearchJournal of Business and Technology, 1 (2), 165-174

Nash, J. C. (2014). On Best Practice Optimization Methods in R. Journal of Statistical Software, 60(2), 1-14.

Parida, V., Westerberg, M., \& Frishammar, J. (2012). Inbound open innovation activities in high-tech SMEs: the impact on innovation performance. Journal of Small Business Management, 50(2), 283-309.

Piperopoulos, P. G. (2012). Entrepreneurship, innovation and business clusters. Gower Publishing, Ltd..

Pontiskoski, E., \& Asakawa, K. (2009). Overcoming barriers to open innovation at Apple, Nintendo and Nokia. World Academy of Science, Engineering and Technology, 53, 372-377.

R Core Team (2014). R: A Language and Environment for Statistical Computing. R Foundation for Statistical Computing, Vienna, Austria. URL http://www.R-project.org/.

Rahman, H., \& Ramos, I. (2010). Open Innovation in SMEs: From closed boundaries to networked paradigm. Issues in Informing

Science and Information Technology, 7(4), 471-487.

Rahman, H., Ramos, I., \& Algoritmi, C. (2013). Challenges in adopting open innovation strategies in SMEs: an exploratory study in Portugal. Issues in informing science and information technology, 10.

Rothwell, R. (1992). Successful industrial innovation: critical factors for the 1990s. R\&d Management, 22(3), 221-240. 
Rush, H., \& Bessant, J. (1992). Revolution in three-quarter time: lessons from the diffusion of advanced manufacturing technologies. Technology Analysis \& Strategic Management, 4(1), 3-19.

Savitskaya, I., Salmi, P., \& Torkkeli, M. (2010). Barriers to open innovation: Case China. Journal of technology management \& innovation, 5(4), 10-21.

Schulze, T., Indulska, M., Geiger, D., \& Korthaus, A. (2012). Idea assessment in open innovation: A state of practice. IDEA, 5, 15-2012.

Spithoven, A., Vanhaverbeke, W., \& Roijakkers, N. (2013). Open innovation practices in SMEs and large enterprises. Small Business Economics, 41(3), 537-562.

Steninger, S. (2014). Open Innovation and Barriers to Adoption, Gothenburg, Sweden, Report No.E2014:091

Team, R. C. (2013). A language and environment for statistical computing. R Foundation for Statistical Computing, Vienna, Austria.
Von Krogh, G., \& Spaeth, S. (2007). The open source software phenomenon: Characteristics that promote research. The Journal of Strategic Information Systems, 16(3), 236-253.

Weerawardena, J. (2003). Exploring the role of market learning capability in competitive strategy. European journal of marketing, 37(3/4), 407-429.

West, J., \& Gallagher, S. (2006). Challenges of open innovation: the paradox of firm investment in open-source software. R\&d Management, 36(3), 319-331.

Westergren, U. H., \& Holmström, J. (2012). Exploring preconditions for open innovation: Value networks in industrial firms. Information and Organization,22(4), 209-226.

Whelan, E., Teigland, R., Donnellan, B., \& Golden, W. (2010). How Internet technologies impact information flows in $R \& D$ : Reconsidering the technological gatekeeper. R\&d Management, 40(4), 400-413. 


\section{Index}

Table 1. OI barriers arranged by theme, by country and by sector for the period 2009-2015

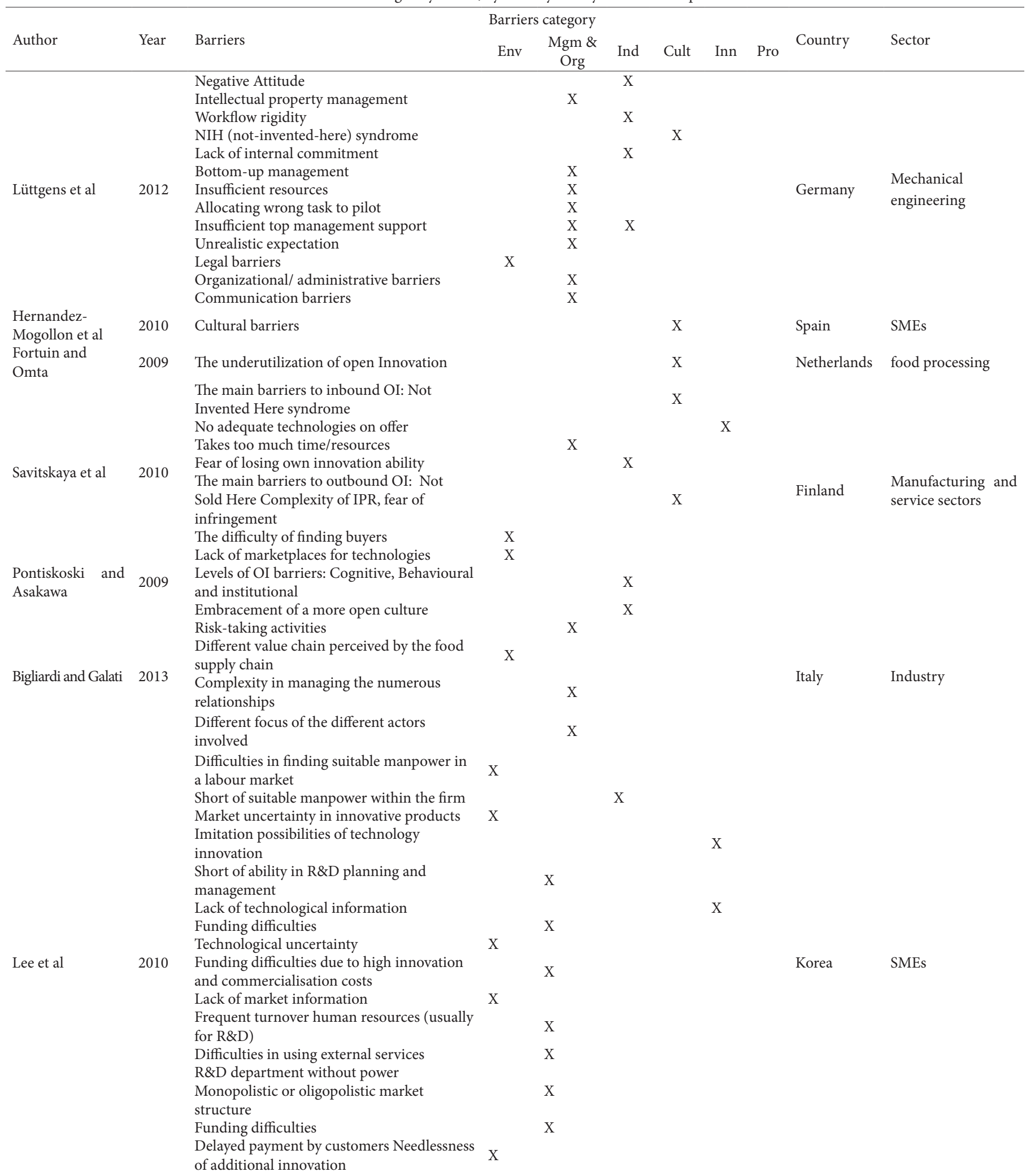




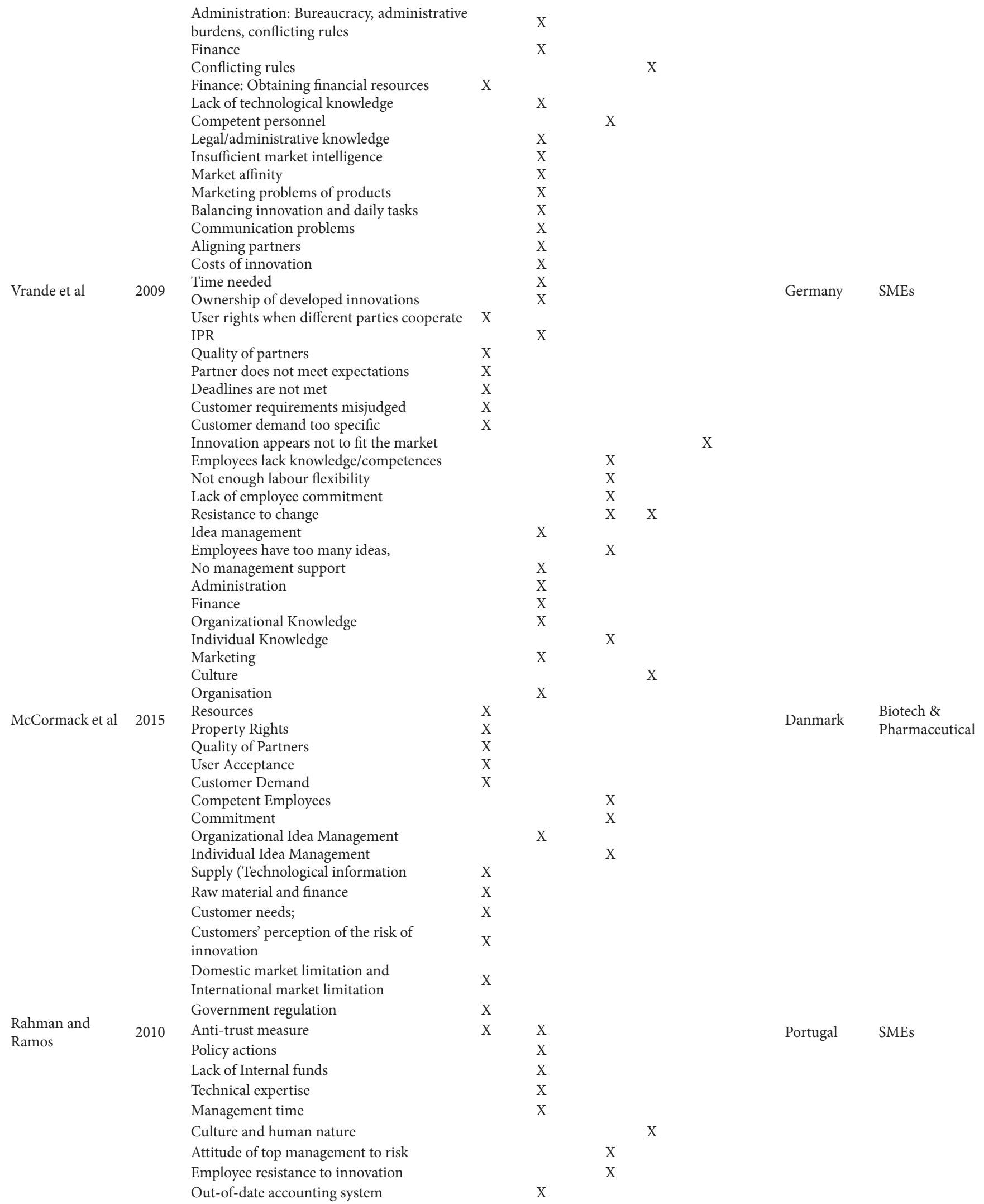

ISSN: 0718-2724. (http://jotmi.org) 


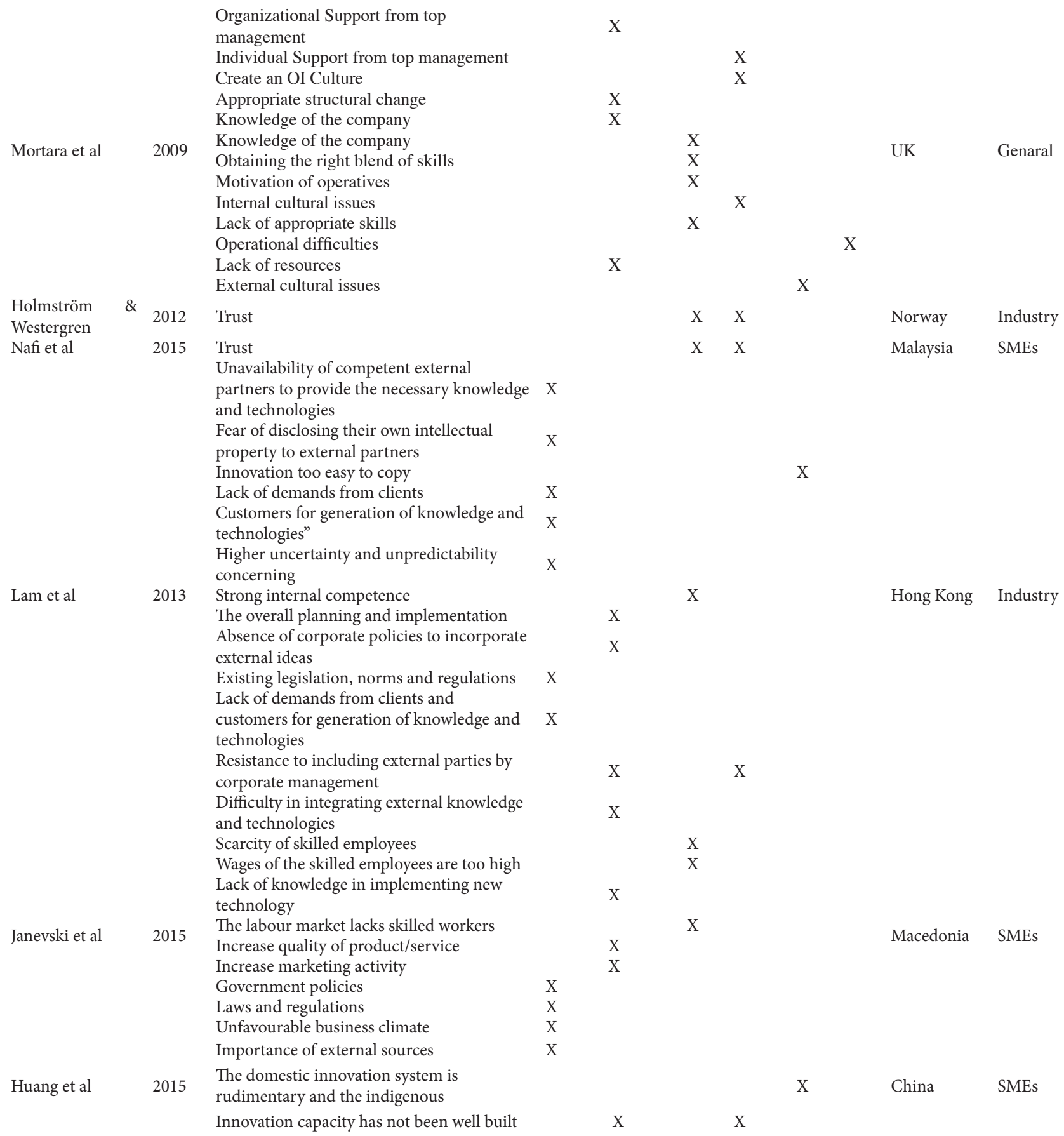


Coras and

Tantau
Workforce Employees resistance to

innovation and change

Poor understanding of their role,

Safety mentality

Insufficient technical expertise or

training of employees

Insufficient knowledge about partners

High staff turnover

Difficulty in finding quality employees

Low support for innovation

Insufficient expertise partners

Ethical barriers

Leaking critical internal resources and

disclosure of core competencies

Conflicting interests of partners

Developing dependency on partners,

relational risk

Lack of trust and communication

among partners

Collaboration suddenly devolved du to partner leaving

Poor quality of partners

Poor management of partnership

Volatile and ambiguous industry

regulation

Unethical behaviour of the partners

Large volume of paperwork

Administrative burdens

Lack of market information and

transparency

Constantly changing needs of the

clients, requiring customized products

Lack of financial capital

High commercialization cost

Higher management

Coordination and control costs

Technology leakage to rival

Technological uncertainty

Inability to adapt to technology

advances

Knowledge spill over

Core knowledge flow towards the

competitors

Inexistence of formal contracts

\section{X $\quad \mathrm{X}$}

$\mathrm{X}$

$\mathrm{X}$

$\mathrm{X}$

$\mathrm{X}$

X X

$\mathrm{X}$

$\mathrm{X}$

$\mathrm{X}$

X

X

X

X

X $\quad \mathrm{X}$

$\mathrm{X}$

X

$\mathrm{X}$

$\mathrm{X}$

Romania Genaral
X

X

$\mathrm{X}$

X

X

X

$\mathrm{X}$

$\mathrm{X}$

$\mathrm{X}$

X

X

X

X

X 


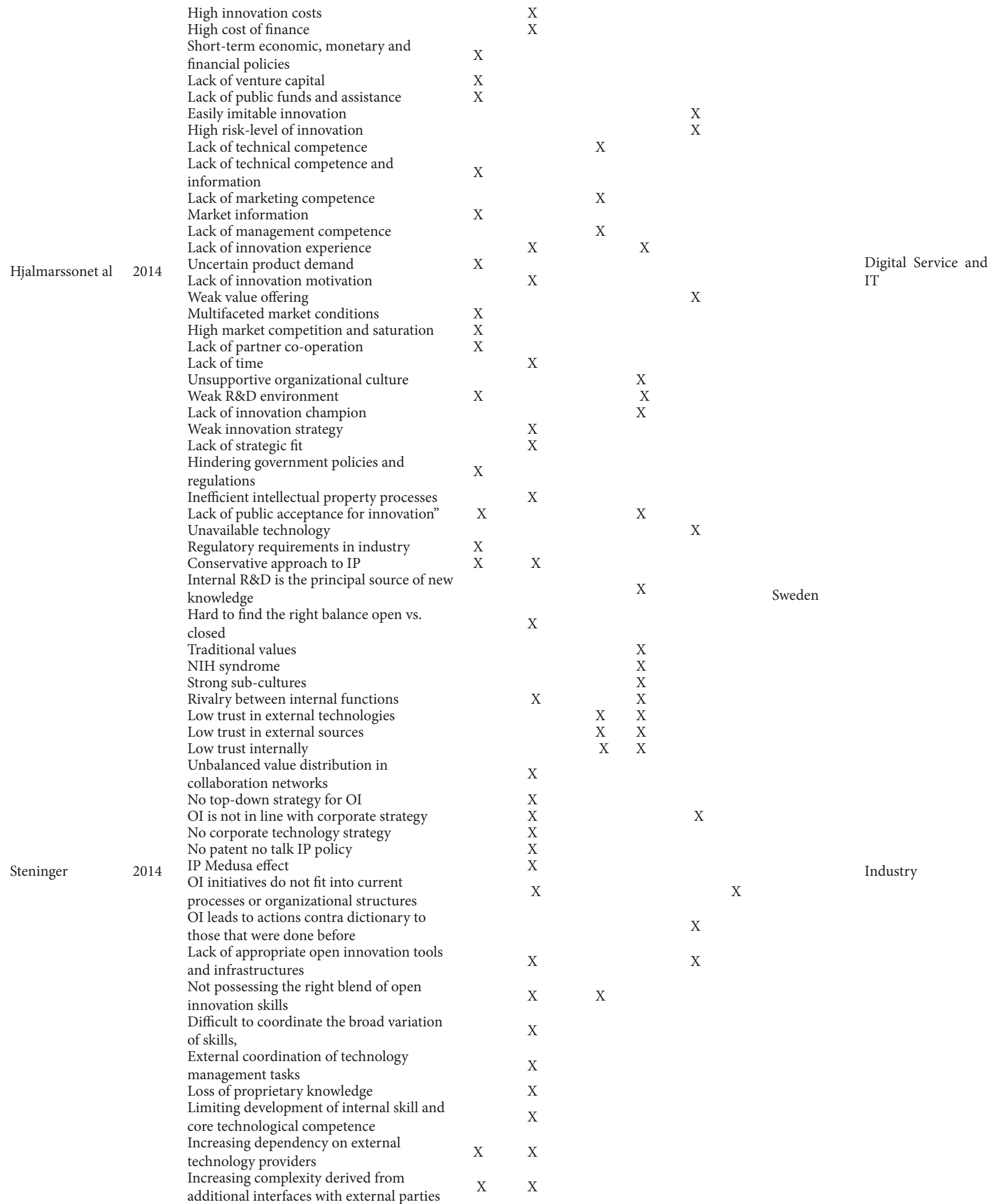

ISSN: 0718-2724. (http://jotmi.org) 